\title{
Synthesis, photophysical and electrochemical properties of perylene dyes
}

\author{
Érica Torres ${ }^{\mathrm{a}, \mathrm{b}}$, Mário Nuno Berberan-Santos ${ }^{\mathrm{b}}$, Maria João Brites ${ }^{\mathrm{a}, *}$ \\ a LNEG, UES Unidade de Energia Solar, Estrada do Paço do Lumiar, 22, 1649-038 Lisboa, Portugal \\ b CQFM-IST, CQFM - Centro de Química-Física Molecular and IN - Institute of Nanoscience and Nanotechnology, Instituto Superior Técnico, \\ Universidade de Lisboa, 1049-001 Lisboa, Portugal
}

\section{A R T I C L E I N F O}

\section{Article history:}

Received 15 April 2014

Received in revised form

1 July 2014

Accepted 18 July 2014

Available online 29 July 2014

\section{Keywords:}

Perylene dyes

Alkyne bridge

Cyanoacetic group

Solar cells

ss-DSCs

Light harvesting materials

\begin{abstract}
A B S T R A C T
Perylene dyes comprising: (i) 4-alkoxyphenylamino moiety in the 9-position as a strong donating group, (ii) cyanoacrylic acid as electron acceptor and anchoring group and (iii) a triple bond as short and rigid linker between perylene core and the acceptor group have been successfully synthesized. Their photophysical (i.e. absorption and emission spectra, molar extinction coefficients, fluorescence quantum yields and lifetime measurements) and electrochemical properties were investigated. The dyes display intense absorption in the visible exhibit high molar absorption coefficients making them good light harvesting materials for ss-DSCs.
\end{abstract}

๑ 2014 Elsevier Ltd. All rights reserved.

\section{Introduction}

Perylene derivatives have been widely applied in various optical devices due to their excellent photophysical properties (e.g. high absorption coefficient and high fluorescence quantum yield), charge transfer properties, as well as outstanding chemical, thermal and photochemical stability [1,2].

Perylene monoimides (PMI) or monoanhydrides (PMA) are being intensively investigated as sensitizers in dye-sensitized solar cells (DSCs) [3]. Keeping only one acceptor group, i.e. imide or anhydride, and introducing a donor group in the 9-position (such as diarylamine) proved to be important in order to obtain a favorable orbital partitioning strength and dipole moment of perylene compounds for DSCs. One way to control optical and electrochemical properties of perylenes dyes is achieved by functionalizing peri and bay positions of perylene core with different substituents. In a simplified view, the peri groups coarsely tune the spectroscopic and electrochemical properties whereas the bay functional groups provide an additional fine tuning [4-7]. To date, the PMA derivative with a bis (4-(2,4,4-trimethylamynopentan-2-yl)phenylamino in 9position and phenylthio groups in 1 and 6 positions of perylene core has shown to be the highest efficient perylene sensitizer in

\footnotetext{
* Corresponding author. Tel.: +351 210924600; fax: +351 217127195.

E-mail address: mjoao.brites@lneg.pt (M.J. Brites).
}

DSCs with liquid electrolyte (iodide/tri-iodide redox couple), delivering an incident monochromatic photo-to-current conversion efficiency of $87 \%$ and yielding a power conversion efficiency of 6.8\% (6 $\mu \mathrm{m}$ thick mesoporous $\mathrm{TiO}_{2}$ film) under standard AM 1.5 solar conditions [8]. In comparison, the same sensitizer tested in solid-state DSC (ss-DSC) yield a power conversion efficiency of only $1.8 \%$ ( $1.8 \mu \mathrm{m}$ thick mesoporous $\mathrm{TiO}_{2}$ film), showing that sensitizer design needs to be adapted according to the cell type.

Based on the aforementioned, the key challenge is to obtain efficiencies that are comparable to that for the optimized $\mathrm{I}^{-} / \mathrm{I}_{3}^{-} /$volatile solvent cell by using a Hole Transport Material (HTM), which may be a solid-state material. However, the poor filling of the mesoporous semiconductor and short diffusion length of charge carriers in HTM have limited the mesoscopic titania layer to a thickness of $2-3 \mu \mathrm{m}$. To increase the amount of light harvesting by ss-DSCs, organic dyes with high molar extinction coefficients, broad absorption in visible spectrum and with suitable geometry for control of molecular orientation and arrangement on the $\mathrm{TiO}_{2}$ surface are needed $[9,10]$.

Here we report the design, synthesis and characterization of new perylene dyes (Scheme 1) comprising: (1) a 4alkoxyphenylamino moiety in the 9-position as a strong donating group, (2) a cyanoacrylic acid as electron acceptor and anchoring group and (3) a triple bond as short and rigid linker between perylene core and the acceptor group. The photophysical and electrochemical properties of these dyes were investigated, and the 